\title{
MOSQUITO NESTS ERADICATION THROUGH MONITORING THE MOSQUITO LARVA (JUMANTIK) BY SCHOOL CHILDREN IN PREVENTING DENGUE HEMORRHAGIC FEVER
}

\author{
Nuurhidayat Jafar ${ }^{1}$, Nur Fadilah ${ }^{2}$, Silvia Malasari ${ }^{3}$, Andina Setyawati4, Moh. \\ Syafar ${ }^{5}$, Andi Wahyuni ${ }^{6}$ \\ 1,2,3,4,5 Fakultas Keperawatan Universitas Hasanuddin \\ ${ }^{6}$ Fakultas Kesehatan Masyarakat Universitas Hasanuddin \\ e-mail:yayat_vieri@yahoo.co.id
}

\begin{abstract}
Background: Dengue Hemorrhagic Fever (DHF) is still a major health problem in Indonesia. Community participation is a key component of DHF control. The group of school children is part of a group of people who can play a strategic role. Establishment of larva monitoring group (Jumantik) and implementation of mosquito nest eradication activity at home and at school. Method: Establishment of larva monitoring group (Jumantik) and implementation of mosquito nest eradication activity at home and at school. Result: As much as nine elementary students and three teachers were formed as jumantik volunteers from three different elementary schools. The result of pre-test of the students, the average score of 8.67 (maximum points $15)$ with the highest score 11 and the lowest score 6 . While the post test results showed an average score 11,89 with the highest score 14 and the lowest score is 10 . The forms of activity for this program were establishment of Jumatik school children, distribution of mosquito eradication kit, and media for health promotion, the establishment of Plan of Action (POA) and the production of second-hand good products. Conclusion: There are several activities that was implemented in this community service program. It is suggested that the school to carry out the activities according to the POA and the community health center can supervise these activities.
\end{abstract}

Keywords: jumantik, dengue hemorrhagic fever, school children, mosquito eradication

\section{PENDAHULUAN}

Demam Berdarah Dengue (DBD) merupakan masalah kesehatan utama di Indonesia, terutama menyerang di wilayah perkotaan (urban), namun tidak menutup kemungkinan juga menyerang di wilayah pedesaan (rural). Hingga saat ini, DBD masih merupakan penyakit yang endemis. Penyakit demam berdarah dengue (DBD) hingga saat ini masih menjadi problem utama di Indonesia. Sekalipun angka kematian DBD dapat ditekan hingga di bawah 1 per 100 orang penderita, namun jumlah dan sebaran kasusnya semakin meningkat. Tahun 2013 jumlah penderita sebanyak 112.511 orang dengan area penyebaran hingga 498 Kabupaten/Kota (Kemenkes,
2014). Jumlah penderita DBD tahun 2016 di menempatkan Sulawesi Selatan dalam salah satu provinsi dengan kejadian luar biasa (KLB) DBD bersama dengan 10 provinsi lainnya di Indonesia (Mon, 2016).

Kementerian Kesehatan telah menetapkan tujuh kegiatan pokok dalam pengendalian DBD antara lain pengobatan dan tatalaksana penderita, pengendalian vektor, peningkatan peran serta masyarakat, jejaring kemitraan, pendidikan dan pelatihan, monitoring dan evaluasi serta penelitian dan pengembangan (Kemenkes, 2014). Dalam mewujudkan tujuh kegiatan pokok pengendalian DBD, ditentukan lima rencana pengembangan program antara lain meningkatkan peran serta 
masyarakat, mengaktifkan kembali kelompok kerja operasional (Pokjanal) DBD di berbagai tingkat administrasi, mendorong kegiatan pemberantasan sarang nyamuk (PSN) oleh anak sekolah dan Pramuka, mendukung pengembangan vaksin serta meningkatkan kemampuan sumber daya manusia(SDM) pengendalian penyakit bersumber arbovirosis (Kemenkes, 2014)

Peran serta masyarakat merupakan komponen utama dalam pengendalian $\mathrm{DBD}$, mengingat vektor DBD nyamuk Aedes jentiknya ada di sekitar pemukiman dan tempat istirahat nyamuk dewasa sebagian besar ada di dalam rumah. Hingga saat ini peran serta masyarakat dalam pelaksanaan pemberantasan sarang nyamuk (PSN) belum optimal, masih banyak masyarakat yang belum melakukan PSN secara rutin. Peran serta masyarakat dalam hal ini adalah peran serta sebagai kader juru pemantau jentik (Jumantik) yang melaksanakan pemantauan jentik PSN yang dilakukan secara rutin seminggu sekali, meliputi kegiatan menguras, menutup dan mengubur atau memanfaatkan kembali barangbarang yang bernilai ekonomis (3M). PSN $3 \mathrm{M}$ secara rutin dapat membantu menurunkan kepadatan vektor, berdampak pada menurunnya kontak antara manusia dengan vektor, akhirnya terjadinya penurunan kasus DBD. Namun berdasarkan Hasil penelitian Wati, Astuti, \& Sari (2016) antara pengetahuan orang tua tentang upaya pencegahan dengan kejadian DBD pada anak yaitu sebagian besar anak positif DBD dengan presentase pengetahuan kurang sebanyak 18 responden $(79,5 \%)$. Hal ini menunjukkan bahwa masih banyak orang tua yang tidak mengetahui bahaya penyakit DBD dan kaitannya dengan pentingnya melaksanakan pencegahan terhadap kejadian DBD melalui usaha-usaha PSN ataupun dengan cara 3M Plus.

Menurut Departemen Kesehatan
RI (2006) sasaran Usaha Kesehatan Sekolah (UKS) meliputi: Sasaran Primer yang merupakan peserta didik. Sasaran Sekunder yang merupakan guru, pamong belajar/tutor orang tua, pengelola pendidikan dan pengelola kesehatan dan sasaran tersier: lingkungan sekolah, keluarga dan masyarakat sekitar sekolah. Kelompok anak sekolah merupakan bagian kelompok masyarakat yang dapat berperan strategis, mengingat jumlahnya sangat banyak sekitar $20 \%$ dari jumlah penduduk Indonesia adalah anak sekolah SD, SLTP dan SLTA. Peran serta anak sekolah sebagai Jumantik dapat digunakan untuk menanamkan perilaku hidup bersih dan sehat (PHBS) pada usia dini, yang akan digunakan sebagai dasar pemikiran dan perilakunya dimasa yang akan datang. Selain itu, menggerakan anak sekolah lebih mudah dibandingkan dengan orang dewasa dalam pelaksanaan PSN.

Jumantik Anak Sekolah adalah anak sekolah dari berbagai jenjang pendidikan dasar yang akan dibina dan dilatih sebagai juru pemantau jentik (Jumantik) di sekolahnya. Pembentukan dan pelaksanaan Jumantik-PSN Anak Sekolah dimaksudkan untuk ikut serta mendukung program pemerintah dalam upaya pemberantasan sarang nyamuk (PSN) penular demam berdarah dengue serta sebagai salah satu upaya pembinaan PHBS sejak usia dini.

Puskesmas Polongbangkeng Utara di Kabupaten Takalar terdiri atas 7 kelurahan /desa yaitu kelurahan Palleko, kelurahan Mattompodalle, kelurahan Malewang, kelurahan Panrannuangku, desa Pa'rampunganta, kelurahan Mannongkoki, desa Parangbaddo. Puskesmas Polongbangkeng Utara telah menjadi lokasi praktek mahasiswa praktek profesi keperawatan komunitas, keperawatan keluarga, dan keperawatan gerontik dari tahun 2012 sampai sekarang. Salah satu 
masalah kesehatan yang ditemukan adalah masalah kesehatan lingkungan dengan vektor terbanyak adalah vektor nyamuk.

Hasil pengkajian mahasiswa praktek profesi keperawatan komunitas tahun 2016 di lingkungan Borong Baji kelurahan Malewang diperoleh vektor paling banyak adalah nyamuk sebesar $42 \%$; lingkungan Bonto Baddo kelurahan Malewang sebesar $46 \%$; lingkungan Malewaya kelurahan Malewang sebesar $39 \%$; lingkungan Malewang kelurahan Malewang sebesar 71 \%; lingkungan Palleko 1 kelurahan Palleko sebesar $33 \%$; lingkungan Mannongkoki kelurahan Mannongkoki sebesar $32 \%$; dusun Lerekang desa Pa'rampunganta sebesar 24,68 \%.

Data penderita DBD di puskesmas Polongbangkeng Utara Kabupaten Takalar tahun 2015 sebesar 23 orang, sementara tahun 2016 meningkat menjadi 24 orang. Hasil wawancara dengan kepala puskesmas Polongbangkeng Utara tentang upaya promotif dan preventif penanggulangan DBD yaitu masih berupa kegiatan penyuluhan di masyarakat, sekolah dan kegiatan surveillance DBD. Jumantik DBD masih dilaksanakan oleh petugas surveillance. Sekolah yang berada di wilayah kerja puskesmas Polongbangkeng Utara khususnya sekolah dasar, semuanya belum memiliki jumantik PSN dari anak sekolah. Terbatasnya jumlah petugas surveillance DBD sebagai jumantik PSN DBD menjadi salah satu faktor kurang optimalnya kegiatan penanggulangan vektor DBD.

\section{METODE}

Pengabdian masyarakat ini dilakukan dengan perekrutan Jumantik Anak Sekolah dan Guru Penanggung Jawab PSN, pelatihan jumantik-PSN anak sekolah, pelatihan dan pembinaan guru penanggung jawab jumantik-PSN anak sekolah, penyediaan PSN kit, pelaksanaan pemantauan jentik dan
PSN di sekolah dan rumah, pelatihan pengolahan barang bekas menjadi barang ekonomis, monitoring dan evaluasi (pencatatan dan pelaporan).

Kegiatan pelatihan jumantik di laksanakan pada hari Jumat tanggal 08 September 2017. Kegiatan ini bertujuan untuk memberikan pelatihan kepada kader-kader Jumantik yang telah dibentuk sebagai bentuk upaya awal dalam mencegah menyebarnya jentik yang menjadi penyebab demam berdarah dengue. Kegiatan ini di ikuti oleh para siswa yang menjadi kader dari 3 sekolah beserta para kepala sekolahnya. Sekolah yang berpartisipasi dalam kegiatan ini antara lain SD Malewang, SD Palleko dan SD Pangembang.

Kegiatan pengabdian masyarakat ini diawali dengan pembetukan tim dan dilakukan pembagian tugas antara tim, menyusun jadwal kegiatan, dan mendiskusikan hal teknis pelaksanaan program. Kegiatan dilanjutkan dengan koordinasi antar sektoral dimana dilakukan untuk membahas penyatuan visi dan misi, keselarasan program, serta keberlanjutan program yang melibatkan sejumlah pihak diantaranya pihak puskesmas, dan pihak sekolah.

Kegiatan ini kemudian dilanjutkan dengan pembukaan yang dirangkaikan dengan pemberian secara simbolis atribut Jumantik kepada kader Jumantik, kemudian dilakukan pelantikan kader jumantik. Sebelumnya dilakukan pengisian pre-test untuk perkembangan dari para kader Jumantik. Setelah itu dilanjutkan dengan pemberian materi pengenalan bahaya demam berdarah dengue, materi tentang Jumantik dan pengisian lembaran tentang keberadaan jentik yang nantinya akan diisi oleh para kader jumantik, dan pemberian materi tentang pengolahan barang bekas dengan dilanjutkan pemutaran video contoh pengolahan barang bekas menjadi barang yang bernilai ekonomi. 


\section{HASIL}

Pada program ini terbentuk 9 orang siswa SD sebagai kader jumantik yaitu dari SD Malewang, SD Palleko dan SD Pangembang (masing masing diwakili 3 siswa), terpilih 3 orang guru penanggung jawab dari setiap sekolah. Hasil pre-test dan post test disajikan pada tabel 1.

Berdasarkan tabel 1, didapatkan bahwa dari 9 siswa didapatkan nilai rata rata 8,67 (poin maksimal 15) dengan nilai tertinggi 11 dan nilai terendah 6. Sedangkan hasil post test didapatkan nilai rata rata 11 , 89 dengan nilai tertinggi 14 dan nilai terendah 10 .
Hasil lain dari program ini yaitu terbentuknya struktur organisasi jumantik PSN Anak Sekolah dan guru penanggung jawab (PJ), telah dibagikan PSN kit (topi, seragam, tas kerja, formulir hasil pemeriksaan jentik, alat tulis, senter, pipet dan plastik tempat jentik dan larvasida), telah dibagikan leaflet, sticker PSN DBD, sertifikat pelatihan kader jumantik PSN Anak Sekolah, adanya SK jumantik PSN Anak Sekolah, adanya SK guru PJ jumantik PSN Anak Sekolah, adanya Plan of Action (POA) jumantik PSN Anak Sekolah, adanya produk ekonomis bersumber barang bekas, dan adanya publikasi media massa.

\begin{tabular}{llll}
\hline & Mean & Min - & Max \\
\hline Pre Test & 8.67 & 6 & 11 \\
Post Test & 11.89 & 10 & 14 \\
\hline
\end{tabular}

Tabel.1. Rerata pengetahuan sebelum dan setelah pelatihan kader Jumantik anak sekolah $(\mathrm{n}=9)$

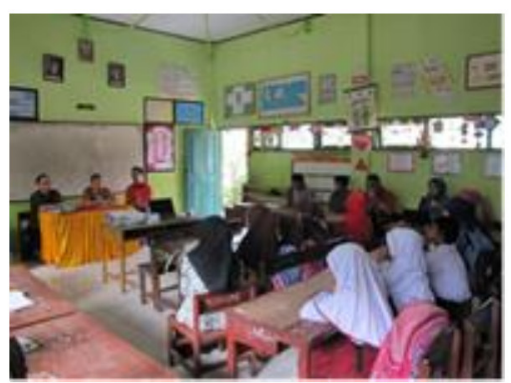

Gambar 1. Pelatihan kader Jumantik Anak Sekolah

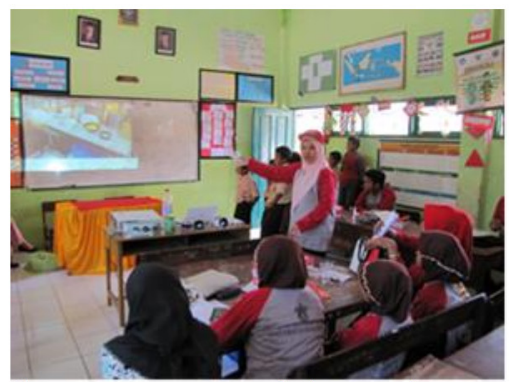

Gambar 3. Pengolahan barang bekas menjadi barang ekonomis

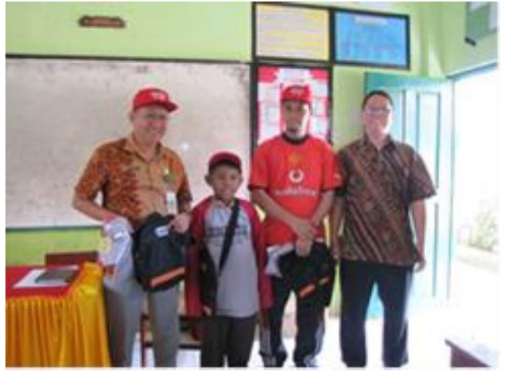

Gambar 2. Pembagian PSN Kit

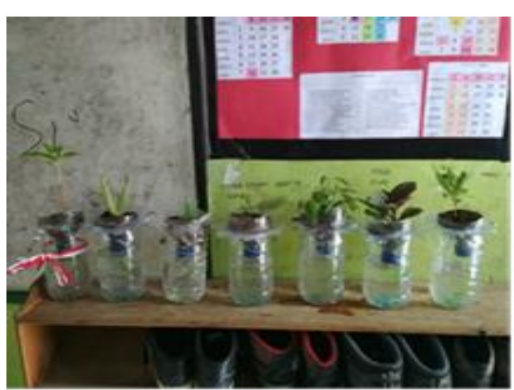

Gambar 4. Produk ekonomis : pot hidroponik 


\section{PEMBAHASAN}

WHO (2002) mengungkapkan bahwa untuk menjalankan strategi pencegahan demam berdarah diperlukan partisipasi dari masyarakat. Masyarakat perlu memiliki pengetahuan dan pemahaman yang baik tentang penyakit demam berdarah. Hal ini diperlukan demi kesuksesan jalannya strategi pencegahan demam berdarah. Beberapa bentuk strategi pencegahan demam berdarah dapat meliputi: Pengendalian lingkungan dimana berkembang biaknya vektor nyamuk aedes aegypti. Ginanjar (2009) mengungkapkan bahwa nyamuk aedes aegypti menyukai tinggal di genangan air yang bersih dan tidak bersentuhan langsung dengan tanah. Jika nyamuk aedes aegypti sudah tinggal digenangan air yang bersih maka ia akan mengembang biakkan telurnya di genangan tersebut. Beberapa tempat genangan air bersih yang disukai oleh vektor demam berdarah dapat berupa sisa kaleng bekas, tempat penampungan air yang terbuka, bak mandi, ban bekas, dan lain sebagainya. Di dalam kegiatan pengabdian masyarakat ini, tim jumatik diajarkan untuk mengobsevasi sejumlah lokasi potensial berkembangnya nyamuk yang berada di sekitar mereka.

Salah satu bentuk strategi pencegahan demam berdarah yaitu melalui Pemberdayaan masyarakat untuk mengendalikan penyebaran penyakit demam berdarah juga telah dilakukan oleh beberapa negara lain. Negara Mexico mengadakan kampanye pencegahan demam berdarah dengan sebutan Patio Limpio. Strategi Patio Limpio dibahas oleh artikel dari Conyer et al (2012) sebagai salah satu upaya pencegahan DBD di masyarakat. Kampanye Patio Limpio memiliki konsep berupa peningkatan partisipasi masyarakat untuk meningkatkan kesadaran tentang DBD. Patio Limpio merupakan kegiatan yang dilakukan dengan cara melatih masyarakat agar mampu mengidentifikasi, mengeliminasi, memonitor, dan mengevaluasi pengembangan vektor dibawah pengawasan pemerintah.

Sekolah merupakan salah satu tempat yang rentan terhadap penyebaran penyakit demam berdarah, hal ini disebabkan karena masih rendahnya angka bebas nyamuk di sekolah-sekolah. Untuk mengurangi penyebaran penyakit demam berdarah di sekolah maka perlu diadakan pemberantasan jentik nyamuk. Akan tetapi pemberantasan jentik nyamuk masih diremehkan oleh beberapa pihak, hal ini dibuktikan dari hasil penelitian Yulianti (2013, dalam Sari, 2016) bahwa berdasarkan parameter pemberantasan jentik nyamuk sebagian responden melakukan PHBS dengan tidak sehat yaitu sebanyak 43 responden $(67,2 \%)$, hal ini disebabkan karena responden tidak memakai lotion anti nyamuk ke sekolah dikarenakan responden beranggapan bahwa nyamuk tidak ada di sekolah. Jadi, indikator vektor (pembawa penyakit) merupakan salah satu indikator yang dapat membentuk lingkungan sekolah yang sehat. Bilamana terdapat vektor (pembawa penyakit) di lingkungan sekolah maka dapat mengakibatkan timbulnya penyakit seperti demam berdarah, malaria, kencing tikus dsb dan nantinya akan berdampak pada seluruh komunitas sekolah.

Hasil penelitian yang dilakukan oleh Ningsih (2014 dalam Sari, 2016) menunjukkan bahwa perilaku hidup bersih dan sehat (PHBS) dipengaruhi dengan kondisi lingkungan sekolah. Begitu pula dengan penelitian Kusuma, et.al. (2013 dalam Sari, 2016) bahwa ada hubungan antara pembinaan lingkungan sekolah sehat dengan pelaksanaan perilaku hidup bersih dan sehat. Jadi, salah satu indeks pencapaian pembinaan lingkungan sekolah yang sehat yaitu terpenuhinya indikator perilaku. Indikator perilaku yang tidak terpenuhi maka akan berdampak pada anggapan masyarakat terhadap sekolah.

Jumantik Anak Sekolah dalam program pengabdian masyarakat ini 
adalah anak sekolah dari berbagai jenjang pendidikan dasar dan menengah yang telah dibina dan dilatih sebagai juru pemantau jentik (Jumantik) di sekolahnya. Pembentukan dan pelaksanaan Jumantik-PSN Anak Sekolah dimaksudkan untuk ikut serta mendukung program pemerintah dalam upaya pemberantasan sarang nyamuk (PSN) penular demam berdarah dengue dan chikungunya serta sebagai salah satu upaya pembinaan perilaku hidup bersih dan sehat (PHBS) sejak usia dini.

Mekanisme pembentukan, pembinaan, pelaksanaan dan pengawasan kegiatannya menjadi hak dan tanggung jawab pemerintah kabupaten/kota dengan mempertimbangkan kebijakan, peraturan dan ketentuan yang ditetapkan oleh pemerintah pusat dan pemerintah provinsi.

PSN adalah tindakan pemberantasan sarang nyamuk melalui kegiatan menutup, menguras danmemanfaatkan barang bekas yang masih berniai (yang dikenal dengan istiah $3 \mathrm{M})$. Kegiatan PSN anak sekolah meliputi pengamatan jentik dan kegiatan 3M (menutup, menguras, memanfaatkan barang-barang bekas yang masih bernilai ekonomis). PSN 3M merupakan kegiatan terencana secara terus menerus dan berkesinambungan. Gerakan ini merupakan kegiatan yang terbilang cukup efektif untuk mencegah terjadinya penyakit DBD serta mewujudkan kebersihan lingkungan dan perilaku hidup sehat.

Sebagai awal dari tahap implementasi kegiatan pengabdian masyarakat ini berupa Pelatihan Kader Juru Pemantau Jentik Pemberantasan Sarang Nyamuk Demam Berdarah Dengue. Kegiatan ini bertujuan untuk memberikan pelatihan kepada kaderkader Jumantik yang telah dibentuk sebagai bentuk upaya awal dalam mencegah menyebarnya jentik yang menjadi penyebab demam berdarah dengue. Kegiatan ini di ikuti oleh para kader kesehatan di 2 kelurahan, yaitu
Kelurahan Malewang dan Kelurahan Palleko.

Hasil pretest dan postest dalam program pengabdian masyarakat ini diperoleh peningkatan pengetahuan dari peserta jumantik. Terdapat peningkatan nilai rata rata 8,67 di awal program dan nilai rata rata 11,89 di akhir program. Dengan peningkatan pengetahuan ini diharapkan kesadaran untuk memberantas nyamuk dan mencegah kejadian DBD juga meningkat.

Dalam program ini setiap pihak memerankan fungsinya masingmasing. Fungsi jumantik yaitu melakukan kegiatan pemantauan jentik dan PSN di lingkungan sekolah secara rutin seminggu sekali, melakukan kegiatan pemantauan jentik dan PSN di lingkungan tempat tinggalnya secara rutin seminggu sekali, membuat catatan/laporan hasil pemantauan jentik dan PSN di sekolah dan tempat tinggalnya, melaporkan hasil pemantauan jentik kepada Guru Penanggung Jawab Jumantik- PSN sekolah seminggu sekali menggunakan Formulir Hasil Pemantauan Jentik Mingguan di Rumah/Tempat Tinggal dan Formulir Hasil Pemantauan Jentik Mingguan di Sekolah, melakukan sosialisasi PSN 3M dan pengenalan DBD kepada rekan-rekan siswasiswi lainnya, berperan sebagai penggerak dan motivator siswa-siswi lainnya agar mau melaksanakan pemberantasan sarang nyamuk terutama di lingkungan sekolah dan tempat tinggalnya, berperan sebagai penggerak dan motivator bagi keluarga dan masyarakat agar mau melaksanakan pemberantasan sarang nyamuk terutama di lingkungan tempat tinggalnya.

Adapun tugas dan fungsi guru penanggung jawab pada program ini yaitu membuat rekapitulasi laporan mingguan hasil Jumantik-PSN di masing-masing rumah siswa dan sekolahnya yang telah disahkan/ ditandatangani oleh kepala sekolah untuk diserahkan kepada kepala 
puskesmas setempat selaku pembina UKS wilayahnya, memeriksa dan mengarahkan kegiatan Jumantik anak sekolah, mengawasi dan memberikan bimbingan teknis kepada Jumantik anak sekolah.

Fungsi Puskesmas yaitu membina dan memantau pelaksanaan kegiatan PSN anak sekolah serta melaksanakan koordinasi dengan pemerintah daerah setempat (Pokja PSN Anak Sekolah), memberikan pembinaan teknis kepada guru-guru dan Jumantik anak sekolah, menganalisa laporan hasil pemantauan jentik oleh Jumantik anak sekolah, melaporkan rekapitulasi hasil pemantauan jentik oleh Jumantik anak sekolah di wilayah kerjanya kepada Pokja PSN Anak Sekolah melalui kepala dinas kesehatan kabupaten/kota.

\section{KESIMPULAN}

Terdapat 6 kegiatan yang terlaksana dalam kegiatan pengabdian masyarakat ini. Semua kegiatan berjalan baik dan lancar. Disarankan agar pihak sekolah melaksanakan kegiatan rutin sesuai POA yang telah disepakati dan pihak puskesmas dapat menjadi pembina bagi kader jumantik yang telah dibentuk

\section{DAFTAR PUSTAKA}

Anderson, E.T. \& McFarlane, J. (2006). Buku ajar keperawatan komunitas : teori dan praktek, Edisi 3. Jakarta : EGC

Conyer, R..T., Galvan, J.M., Zuniga, P.B. (2012). Community participation in the prevention and control of dengue: the patio limpio strategy in Mexico, Pediatrics and International Child Health, Vol. 32, p. $10-13$

Departemen Kesehatan RI (2006). Petunjuk pelaksanaan monitoring evaluasi dan pelaporan UKS. Retrieved September 19, 2015, from www.depkes.go.id

Ginanjar, G. (2009). Demam berdarah. Jakarta: PT. Mizan Publika

Kemenkes RI (2011). Modul pengendalian demam berdarah dengue. Direktorat Jenderal Pengendalian Penyakit dan Penyehatan Lingkungan.

Kemenkes RI. (2013). Pengendalian demam berdarah dengue untuk pengelola program dbd di Puskesmas. Direktorat Jenderal Pengendalian Penyakit dan Penyehatan Lingkungan.

Kemenkes. (2014). Petunjuk teknis jumantik psn anak sekolah. 1-37.

Mon (2016). Wilayah kejadian luar biasa demam berdarah dengue ada di 11 provinsi. Retrieved from: http://www.depkes. go.id/development/site/dinaskesehatan/ index.ph p ? view $=$ print $\&$ cid $=1$ $16031100028 \&$ \&id=wilayah-klb-dbd-adadi-11-provinsi

Sari, H, Jafar, N, \& Malasari, S. (2017). Healthy environment development in school health units of public primary schools in Bontobahari Bulukumba. Indonesian Contemporary Nursing Journal (ICON Journal). 1 (2), 76-85. Retrieved from http://journal.unhas.ac.id/index.php/ icon/article/view/3448

Wati, N. K., Astuti, S., \& Sari, L. K. (2016). Hubungan Pengetahuan dan Sikap Orang Tua tentang Upaya Pencegahan dengan Kejadian DBD pada Anak di RSUD Banjarbaru Tahun 2015. Jurkessia, 2425.

World Health Organization. (2002). Pencegahan dan pengendalian dengue dan demam berdarah: panduan lengkap. Jakarta: EGC 